\title{
Accuracy of emergency physician performed bedside ultrasound in determining gestational age in first trimester pregnancy
}

\author{
Turandot Saul ${ }^{1 *}$, Resa E Lewiss ${ }^{1}$ and Marina Del Rios Rivera ${ }^{2}$
}

\begin{abstract}
Background: Patient reported menstrual history, physician clinical evaluation, and ultrasonography are used to determine gestational age in the pregnant female. Previous studies have shown that pregnancy dating by last menstrual period (LMP) and physical examination findings can be inaccurate. An ultrasound performed in the radiology department is considered the standard for determining an accurate gestational age. The aim of this study is to determine the accuracy of emergency physician performed bedside ultrasound as an estimation of gestational age (EDUGA) as compared to the radiology department standard.

Methods: A prospective convenience sample of ED patients presenting in the first trimester of pregnancy (based upon self-reported LMP) regardless of their presenting complaint were enrolled. EDUGA was compared to gestational age estimated by ultrasound performed in the department of radiology (RGA) as the gold standard. Pearson's product moment correlation coefficient was used to determine the correlation between EDUGA compared to RGA.
\end{abstract}

Results: Sixty-eight pregnant patients presumed to be in the 1st trimester of pregnancy based upon self-reported LMP consented to enrollment. When excluding the cases with no fetal pole, the median discrepancy of EDUGA versus RGA was 2 days (interquartile range (IQR) 1 to 3.25). The correlation coefficient of EDUGA with RGA was 0.978. When including the six cases without a fetal pole in the data analysis, the median discrepancy of EDUGA compared with RGA was 3 days (IQR 1 to 4). The correlation coefficient of EDUGA with RGA was 0.945.

Conclusion: Based on our comparison of EDUGA to RGA in patients presenting to the ED in the first trimester of pregnancy, we conclude that emergency physicians are capable of accurately performing this measurement. Emergency physicians should consider using ultrasound to estimate gestational age as it may be useful for the future care of that pregnant patient.

Keywords: Gestational age dating, Bedside ultrasound, First trimester pregnancy

\section{Background}

Pregnant females commonly present to the emergency department (ED) with complaints of pain, bleeding, or other symptoms that necessitate an evaluation to determine the presence of an intra-uterine pregnancy or determine the viability of the pregnancy. The ED is often where the first evaluation of a pregnancy takes place.

\footnotetext{
* Correspondence: turan@joshsaul.com

'Department of Emergency Medicine, Emergency Ultrasound Division, St. Luke's/Roosevelt Hospital Center, 1000 10th Avenue, New York, NY 10019, USA

Full list of author information is available at the end of the article
}

Three methods used to estimate gestational age (GA) are menstrual history, clinical examination, and ultrasonography. Previous studies have shown that women cannot provide accurate information about their LMP, can have irregular cycle lengths, and can have irregular ovulation from cycle to cycle, making GA dating calculated by LMP often inaccurate $[1,2]$. The size of the uterus can be assessed by pelvic examination, but factors such as the presence of fibroids can make this determination difficult. Clinical evaluation by palpation of the gravid uterus increases in accuracy after the first trimester of pregnancy when the uterus rises above the pelvic 
brim. Ultrasound in the hands of an experience operator is the most accurate means of determining GA [3-6].

First trimester GA is calculated from the gestational sac diameter [7-11] when no fetal pole is yet visible or the fetal crown-rump length (CRL) once it is visualized. The CRL is a sonographic measurement of the length of the fetal pole from the crown to the rump, not including the yolk sac. The following formula can be used: gestational age $=5.2876+(0.1584 \mathrm{x} \times \mathrm{CRL})-(0.0007 \times$ $\mathrm{CRL}^{2}$ ); however, most ultrasound machines have a biometric formula software package that can perform this calculation [12]. The correlation between these measurements in the first trimester has been shown to be excellent with an estimated 95\% confidence interval of plus or minus 5 days [13]. Several other studies have shown that when CRL is measured between 7 and 10 weeks gestation, the method is accurate within 3 days [14-17]. The first trimester is the optimal time to estimate gestational age when biologic variation in size from fetus to fetus is minimal [18].

Shah et al. reported that emergency physicians can use bedside ultrasound to estimate gestational age in the second and third trimesters of pregnancy as this can be important in trauma and other emergency scenarios [19]. Our study aims to determine the accuracy of emergency physician performed bedside ultrasound as an estimation of gestational age (EDUGA) as compared to the radiology department standard.

\section{Methods}

This was a prospective, convenience sample of pregnant women presenting to the ED for evaluation. Potential participants were identified by the computerized patient tracking system either by stated pregnancy history or by a positive urine pregnancy test. All pregnant women who were thought to be in the first trimester of pregnancy were eligible regardless of their ED presenting complaint. Patients were excluded if they were clinically unstable or required emergent transportation to the operating room, or they were unable or unwilling to give consent. The Institutional Review Board for our hospital approved the study.

The study was performed at a large, urban hospital center with a 3-year emergency medicine residency program. The median age of enrolled patients was 27 years, and 34\% identified themselves as African American, 19\% as Caucasian, $43 \%$ as Hispanic, and $1 \%$ as Asian. All residents and attending physicians received training in how to perform a crown-rump length measurement and estimate gestational age through a 30-min didactic lecture and 1-h hands-on ultrasound training session. Prior to the training, all participating attending physicians were credentialed by the department to perform pelvic ultrasound for first trimester of pregnancy indications.

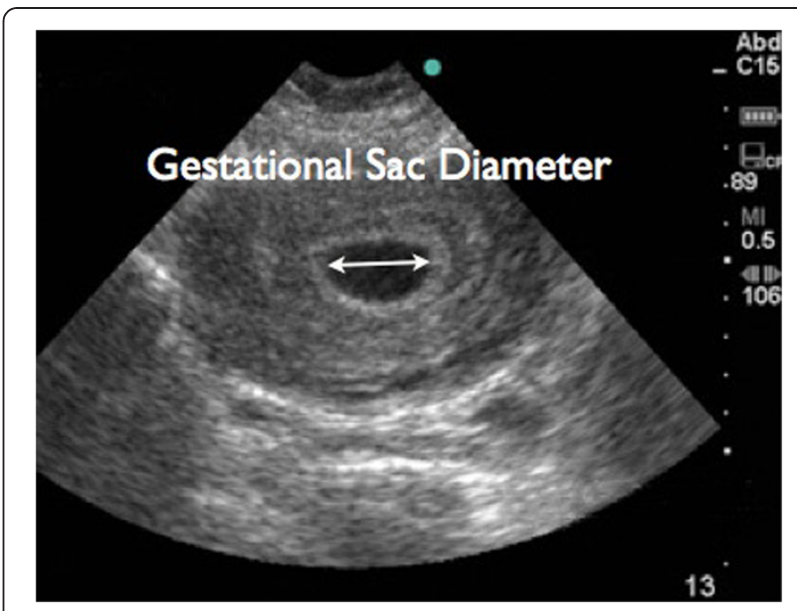

Figure 1 Trans-abdominal ultrasound image showing measurement of gestational sac diameter.

Resident physicians had varied previous ultrasound experience based upon their level of training.

All studies were performed using SonoSite Titan (SonoSite, Inc., Bothell, WA, USA) using either a 2 to 4 $\mathrm{MHz}$ tight curvilinear probe for trans-abdominal scanning or a 5 to $8 \mathrm{MHz}$ endocavitary probe for transvaginal scanning. Trans-abdominal and/or trans-vaginal ultrasound was performed at the discretion of the attending physician. Measurements were obtained in either a sagittal or transverse plane. In cases where no fetal pole was visualized, caliper measurements were performed of the gestational sac diameter (Figure 1). When a fetal pole was visualized, caliper measurements were performed of the maximal crown-rump length, and the obstetrical software package calculated the GA (Figures 2 and 3). Demographics were collected from the patients as well as their last reported normal LMP.

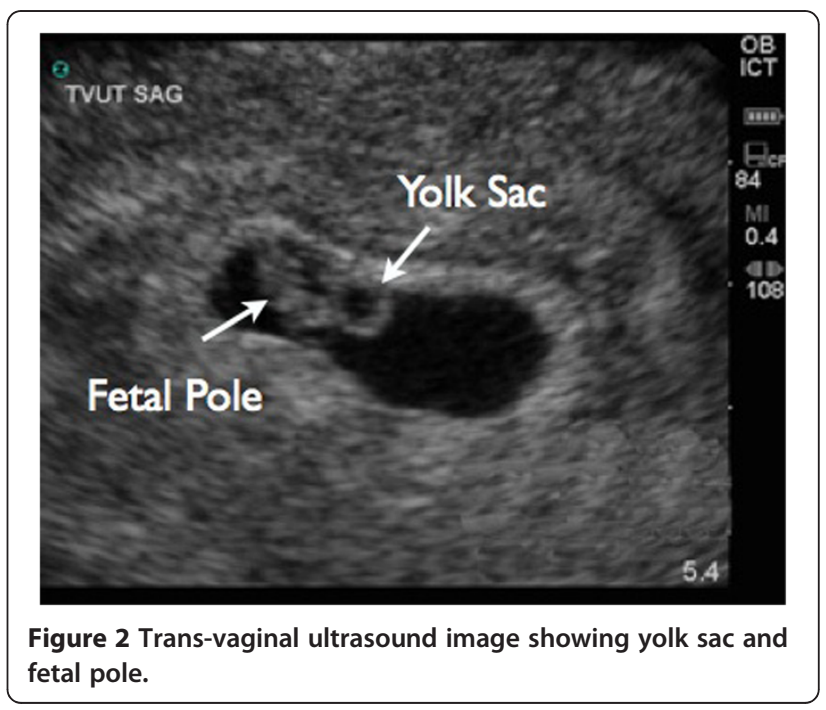




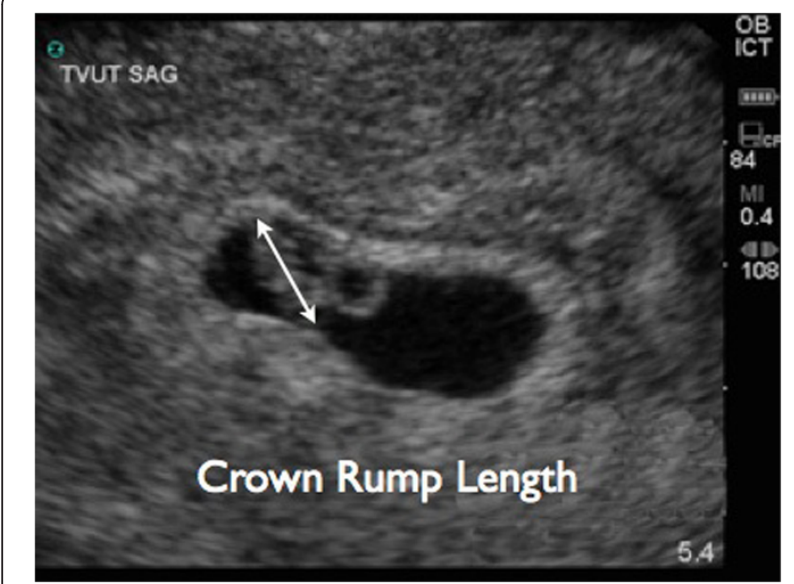

Figure 3 Trans-vaginal ultrasound image demonstrating crownrump length measurement.

The level of training (PGY-1, PGY-2, PGY-3, Attending) of the sonographer was recorded. RGA results were collected via real-time or retrospective reporting from the radiologist. Patients presenting to the ED during hours the radiology department ultrasound suite was closed were given instructions to return the following morning for their radiology department ultrasound. The medical record was reviewed for results of these scans performed the following morning. Any patient who did not have their radiology department performed study at our institution was excluded. For all EDUGA scans, thermal images were printed and submitted for review. One investigator reviewed all the EDUGA still images for technical adequacy.
We expected that the EDUGA would have a correlation with the RGA of 0.5 . In order to achieve an alpha of 0.01 and beta of $0.05,62$ patients had to be enrolled. We enrolled over a 6-month time period expecting to have some loss to follow up. Statistical analysis was performed using $R$ statistical software (version 2.12.1 for Mac; The $\mathrm{R}$ Foundation for Statistical Computing, http://www.R-project.org). Our primary outcome measure was the accurate determination of EDUGA using RGA as the gold standard. Pearson's product moment correlation coefficient was used to determine the correlation between EDUGA and RGA.

\section{Results}

Eighty-five patients met inclusion criteria for enrollment. Four patients did not consent to participate. Eighty-one patients were enrolled in the study. Thirteen patients did not return for a follow-up formal radiology department ultrasound within $24 \mathrm{~h}$ of EDUGA after they were seen during hours when the department of radiology was closed. Sixty-eight participants were included in our study (Figure 4). Patient characteristics are listed in Table 1.

Out of the 68, 30 (44\%) ultrasounds were performed by attending physicians, 19/68 (28\%) by PGY-3 residents, $11 / 68(16 \%)$ by PGY-2 residents, and 8/68 (12\%) by PGY-1 residents. Absence of a fetal pole was found in six patients. Absence of a fetal pole does not exclude the possibility of an early intra-uterine pregnancy. It is for this reason that data was analyzed twice. In the first analysis, cases with absence of a fetal pole were excluded $(N=62)$. In the second analysis, all cases were included $(N=68)$.

When excluding the six cases with no fetal pole, the median discrepancy of EDUGA versus RGA was 2 days

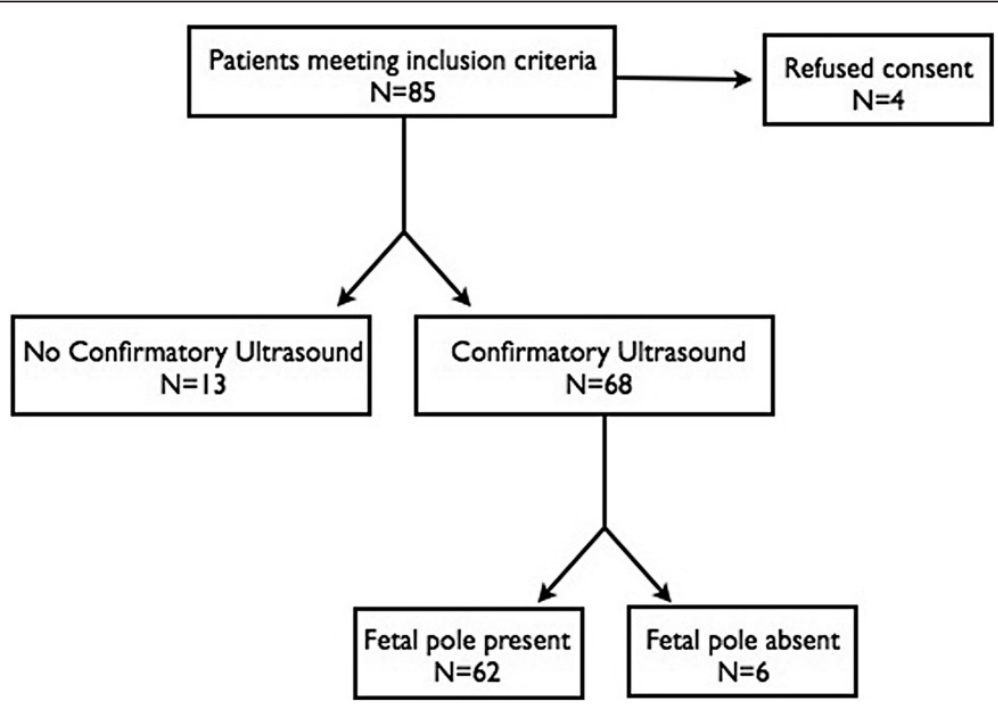

Figure 4 Flow diagram of enrolled patients. 
Table 1 Patient characteristics

\begin{tabular}{ll}
\hline Patient characteristics & Number \\
\hline Age, years, median (range) & $27(16$ to 41) \\
Gestational age by LMP, weeks, median (IQR) & $71 / 7(62 / 7$ to $83 / 7)$ \\
Ethnicity, N (\%) & \\
African American & $23(34 \%)$ \\
Caucasian & $13(19 \%)$ \\
Hispanic & $29(43 \%)$ \\
Asian & $1(1 \%)$ \\
Not reported & $2(3 \%)$ \\
\hline
\end{tabular}

LMP, last menstrual period; IQR, interquartile range.

(IQR 1 to 3.25) (Table 2). The correlation coefficient of EDUGA with RGA was 0.978. The scatter plot in Figure 5 illustrates the differences between the discrepancies by EDUGA compared to RGA.

When including the six cases without a fetal pole in the data analysis, the median discrepancy of EDUGA compared with RGA was 3 days (IQR 1 to 4). The correlation coefficient of EDUGA with RGA was 0.945.

\section{Discussion}

Based on our comparison of EDUGA to RGA in patients presenting to the ED in the first trimester of pregnancy, we conclude that after a brief training, emergency physicians are capable of accurately performing this measurement. This estimation of GA may be more accurate than those made by calculations based on LMP or physical examination findings. The emergency department is, for many, the first time the evaluation of pregnancy takes place, and some patients may not present for routine prenatal care until later in the pregnancy. Since GA dating is most accurate in the first trimester, this may be a useful data point for the future care of that pregnancy. Emergency physicians should consider using ultrasound to estimate gestational age when evaluating these patients.

\section{Limitations}

Physicians that were trained to do these measurements already had a background in pelvic sonography in first trimester pregnancy. At our institution, attending physicians have performed at least 25 previous pelvic

Table 2 Comparison of EDUGA dating with RGA

\begin{tabular}{lll}
\hline & $\begin{array}{l}\text { EDUGA (no fetal } \\
\text { pole excluded) }\end{array}$ & EDUGA (all cases) \\
\hline $\begin{array}{l}\text { Discrepancy with RGA, } \\
\text { days, median (IQR) }\end{array}$ & $2(1$ to 3.25$)$ & $3(1$ to 4$)$ \\
$\begin{array}{l}\text { Correlation coefficient } \\
(95 \% \mathrm{Cl})\end{array}$ & 0.978 (0.965 to 0986) & 0.945 (0.909 to 0.966) \\
$P$ value & $p<0.005$ & $p<0.005$ \\
\hline
\end{tabular}

$\mathrm{IQR}$, interquartile range; $\mathrm{Cl}$, confidence interval.

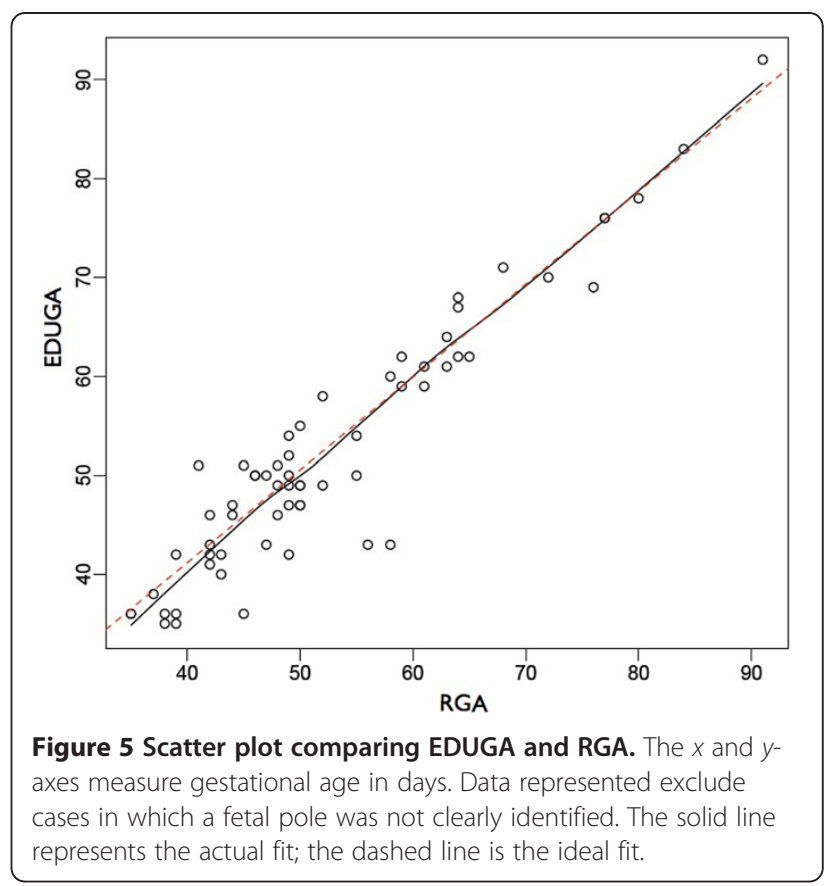

sonograms, and residents have exposure early in their residency. Physicians with less prior exposure may require additional training to be able to perform this measurement with a high degree of accuracy. Also, given the convenience sample design of this study, physicians who enrolled patients in the study may have had a greater interest in ultrasound and a higher level of performance than other colleagues who did not enroll patients. In addition, our patient population, age, and ethnicity groups may not be generalizable to other emergency medicine practice populations.

\section{Conclusion}

After a brief training session, emergency physicians are capable of accurately estimating gestational age compared to radiology department ultrasound and should consider performing these measurements in the first trimester of pregnancy.

\section{Competing interests}

The authors declare that they have no competing interests.

\section{Authors' contributions}

TS was responsible for the study conception and design, data acquisition, and drafting of the manuscript. REL designed the study, acquired the data, and drafted the manuscript. MDR was responsible for supervision of study design, statistical analysis and interpretation, manuscript preparation, and general supervision of the project. All authors read and approved the final manuscript.

\section{Author details}

${ }^{1}$ Department of Emergency Medicine, Emergency Ultrasound Division, St. Luke's/Roosevelt Hospital Center, 1000 10th Avenue, New York, NY 10019, USA. ${ }^{2}$ Department of Emergency Medicine, College of Medicine, University of Illinois at Chicago, 808 South Wood Street, 476C CME, Chicago, IL 60612, USA. 


\section{References}

1. Geirsson RT (1991) Ultrasound instead of last menstrual period as the basis of gestational age assignment. Ultrasound Obstet Gynecol 1(3):212-219

2. Geirsson RT, Busby-Earle RM (1991) Certain dates may not provide a reliable estimate of gestational age. Br J Obstet Gynaecol 98(1):108-109

3. Gardosi J, Geirsson RT (1998) Routine ultrasound is the method of choice for dating pregnancy. Br J Obstet Gynaecol 105(9):933-936

4. Mongelli M, Wilcox M, Gardosi J (1996) Estimating the date of confinement: ultrasonographic biometry versus certain menstrual dates. Am J Obstet Gynecol 174:278

5. Neilson JP (2000) Ultrasound for fetal assessment in early pregnancy Cochrane Database Syst Rev 2:CD000182

6. Yang H, Kramer MS, Platt RW, Blondel B (2002) How does early ultrasound scan estimation of gestational age lead to higher rates of preterm birth? Am J Obstet Gynecol 186:433

7. Mettler FA Jr (2005) Genitourinary system and retroperitoneum. In: Mettler FA (ed) Essentials of radiology, 2nd edn. Saunders, Philadelphia, pp 213-252

8. Williams DE, Pridjian G (2011) Obstetrics. In: Rakel RE (ed) Textbook of family medicine, 8th edn. Saunders, Philadelphia, pp 360-400

9. Hansmann M, Hackelöer BJ, Staudach A, Wittmann BK (1986) Ultrasound diagnosis in obstetrics and gynecology. Springer, New York

10. Nyberg DA, Hill LM, Böhm-Velez M, Mendelson EB (eds) (1992) Transvaginal ultrasound, vol 76. Mosby, St. Louis

11. University T (1982) Gestational weeks and computation methods. Ultrasound Imaging Diagn 12:1

12. Westerway SC, Davison A, Cowell S (2000) Ultrasonic fetal measurements: new Australian standards for the new millennium. Aust N Z J Obstet Gynaecol 40(3):297-302

13. Wisser J, Dirschedl P, Krone S (1994) Estimation of gestational age by transvaginal sonographic measurement of greatest embryonic length in dated human embryos. Ultrasound Obstet Gynecol 4:457-462

14. Goldstein SR, Wolfson R (1994) Endovaginal ultrasonographic measurement of early embryonic size as a means of assessing gestational age. J Ultrasound Med 13:27

15. Robinson HP, Fleming JE (1975) A critical evaluation of sonar "crown-rump length" measurements. Br J Obstet Gynaecol 82:702

16. Robinson HP (1973) Sonar measurement of fetal crown-rump length as a means of assessing maturity in first trimester pregnancy. Br Med J 4:281

17. Drumm JE, Clinch J, MacKenzie G (1976) The ultrasonographic measurement of fetal crown rump length as a method of assessing gestational age. Br J Obstet Gynaecol 83:417

18. Liang FC, Frates MC (2000) Ultrasound evaluation during the first trimester of pregnancy. In: Callen PW (ed) Ultrasonography in obstetrics and gynecology, 4th edn. Saunders, Philadelphia

19. Shah S, Teismann N, Zaia B, Vahidnia F, River G, Price D, Nagdev A (2010) Accuracy of emergency physicians using ultrasound to determine gestational age in pregnant women. Am J Emerg Med 28(7):834-838

doi:10.1186/2036-7902-4-22

Cite this article as: Saul et al:: Accuracy of emergency physician performed bedside ultrasound in determining gestational age in first trimester pregnancy. Critical Ultrasound Journal 2012 4:22.

\section{Submit your manuscript to a SpringerOpen ${ }^{\circ}$ journal and benefit from:}

- Convenient online submission

- Rigorous peer review

- Immediate publication on acceptance

- Open access: articles freely available online

- High visibility within the field

- Retaining the copyright to your article

Submit your next manuscript at $\gg$ springeropen.com 